\title{
A Teoria de Gaia
}

Igor Zanoni Constant Carneiro Leão*

Denise Maria Maia

RESUMO - Este texto resenha as ideias centrais concernentes à Teoria de Gaia tal como exposta por seu maior criador, sir James Lovelock. Essas ideias estão relacionadas à ação antrópica sobre nosso ambiente natural de uma ameaça decisiva à vida como a conhecemos hoje em nosso capitalismo avançado. Gaia se refere, pois, aos nossos conceitos de desenvolvimento, valores éticos e morais ao controverter o que se tem entendido por desenvolvimento sustentável.

Palavras-chave: Gaia. Sustentabilidade. Ecologia. Desenvolvimento.

A teoria de Gaia é uma concepção científica do sistema Terra, a Terra vista como autorreguladora com a comunidade de organismos vivos no controle. Ela foi desenvolvida principalmente pelo médico e cientista britânico James Lovelock, hoje com mais de noventa anos, mas ainda ativo e independente pesquisador das questões ambientais que afetam a Terra e seus habitantes na atualidade. Crítico bastante fundamentado, seja do estilo de vida que a civilização consagrou, econômica e tecnologicamente, seja do movimento verde que procura por formas equivocadas corrigir os danos à vida que esse estilo implica. Este texto explora algumas de suas ideias em seus últimos dois livros publicados no Brasil, A Vingança de Gaia (2006) e Gaia: Alerta Final (2010). Ele é uma contribuição ao entendimento das relações entre desenvolvimento e meio ambiente, colocando em xeque a concepção de desenvolvimento sustentável.

A teoria de Gaia começou a ser desenvolvida em um artigo de 1965, publicado quando Lovelock trabalhava no Laboratório de Propulsão a Jato da Califórnia, no qual se especulava que, sendo a atmosfera da Terra uma agregação biológica, é razoável pensar que seus componentes são mantidos em uma composição química ideal ou próxima do ideal para o ecossistema. Se isto é verdade, também o clima da Terra deve ser mantido próximo de um ideal para o ecossistema. Assim, nasceu a hipótese de Gaia que deu origem à teoria de Gaia.

\footnotetext{
* Doutor em Economia pela Universidade Estadual de Campinas - UNICAMP. Professor do Departamento de Economia da Universidade Federal do Paraná - UFPR. Endereço eletrônico: igorzaleao@yahoo.com.br.

** Doutora em Educação pela Universidade Federal de Minas Gerais - UFMG. Professora do Departamento de Economia da Universidade Federal do Paraná - UFPR. Endereço eletrônico: denimaia@ufpr.br.
} 
Ela consiste na ideia de que a química, física e biologia presentes no planeta fizeram dela um organismo vivo, capaz de regular sua temperatura e seus elementos químicos, de modo a favorecer a vida; e vai além ao complementar a Teoria da Evolução que consiste na ideia central de seleção adaptativa dos seres diante do ambiente. A Teoria de Gaia defende que a interação entre a biosfera e todos os componentes da Terra, como sua geologia, mantêm a vida regulando o clima ou os elementos químicos ideais para a vida. Como dizia o artigo,

\footnotetext{
É interessante perguntar: por que a concentração do oxigênio é mantida em $21 \%$ ? É um fato que a energia necessária para ignição de compostos orgânicos muda em cerca de $70 \%$ a cada mudança de $1 \%$ na concentração de oxigênio no nível atmosférico. Vida, mesmo a $25 \%$ de oxigênio, poderia ser bem incômoda, especialmente para as árvores. A remoção de oxigênio pela relva ou incêndios florestais pode definir o limite superior de $21 \%$, mas parece mais provável que o oxigênio seja ativamente controlado em um máximo seguro.
}

Nesse sentido, a composição atmosférica da Terra é mantida em um estado dinamicamente estável pela presença da vida; além disso, os organismos afetam a composição atmosférica, regulando o clima da Terra para mantê-la favorável à vida. Essa regulação teria sido necessária para preservar a habitabilidade do planeta diante do aquecimento do Sol desde que a vida começou há 3,5 bilhões de anos.

Essa percepção foi trabalhada a seguir no início dos anos 70 por Lynn Margulis, em Boston, que destacou a importância dos micro-organismos na evolução do planeta. Isto porque, durante dois ou três bilhões de anos, todas as formas de vida na Terra eram de microorganismos, somente nos últimos quinhentos a novecentos milhões de anos os organismos multicelulares começaram a ter importância. A partir daí vários cientistas trabalharam nesses ensaios, defendendo que a regulação poderia ser explicada pela geoquímica e pelo intemperismo biogeoquímico, isto é, pela reação de rochas e seres vivos autorregulando a remoção do dióxido de carbono do ar e promovendo um equilíbrio próximo do ideal para o crescimento vegetal. Nestas discussões, defesas e críticas dessa hipótese foram feitas por muitos outros cientistas e, a hipótese de Gaia se tornou uma teoria, no sentido de que o regulador da química da atmosfera e do clima é o sistema Terra inteiro, feito de vida, inclusive o ar, os oceanos e as rochas superficiais, além dos organismos isoladamente. Essa visão foi aperfeiçoada por modelos computacionais procurando provar que os organismos, ao contrário da concepção darwiniana, não evoluem independentemente de seu ambiente, mas fazem parte de um todo maior que inclui o ambiente físico e químico que eles e outros organismos alteram. 
A terra teria se regulado para uma temperatura bem mais fria que a atual e para uma população significativamente menor, em relação com a radiação recebida do sol e a presença de gases letais como o carbono. Entretanto, desde o ano de 1800, quando a população humana era de um bilhão de seres, o planeta recebeu o aumento significativo de pessoas, e animais para consumo alimentar, ao mesmo tempo em que se alteraram a paisagem natural e as condições de vida dos oceanos. Este fenômeno está ligado ao desenvolvimento socioeconômico, baseado em larga medida na queima de combustíveis fosseis, em um processo de aquecimento global, talvez irreversível para a vida atualmente conhecida na Terra.

$\mathrm{Na}$ teoria de Gaia a finalidade da autorregulação é a manutenção da habitabilidade do planeta, isto é, mantê-lo bem arrumado e com um balanço disciplinado de energia. A partir daí pôde-se perceber como Gaia resiste às intervenções humanas através de uma aurorregulação opondo-se ao modo como os homens alteram o ar com gases de efeito estufa e removem sua cobertura natural de florestas para lavoura. Atualmente as intervenções humanas são potentes e parecem inviabilizar o sistema Terra tal como conhecemos hoje. $\mathrm{O}$ sistema parece estar caminhando para um estado quente com um clima estável com Gaia se autorregulando e sobrevivendo com uma biosfera reduzida.

Essa concepção vê a Terra como um grande organismo vivo, dentro de um pensamento holístico que congrega fisiologistas, engenheiros e físicos que entendem ser crucial maior conhecimento para saber como reagir aos danos a ela infligidos para a sua e nossa proteção. Ou seja, o entendimento correto da Terra como um planeta vivo é uma questão crucial para a existência de bilhões de pessoas e de extinção para toda uma gama de espécies.

A relevância dessas discussões está na percepção da crescente abundância dos gases de efeito estufa provindos da indústria e da agricultura, inclusive gases de ecossistemas naturais danificados pelo aquecimento global no Ártico e nos trópicos. Os ecossistemas oceânicos não são mais capazes de remover o dióxido de carbono porque a sua acidificação tornou o oceano deserto à medida que se aquece. A absorção extra do calor radiante do Sol como derretimento de calotas polares amplifica o aquecimento e dificulta a estabilização do nível de dióxido de carbono e da temperatura. Como propõe Lovelock,

A pressuposição de que o clima pode ser estabilizado por uma redução nas emissões em uma abundância de dióxido de carbono a 550 ppm e uma temperatura global $2 \%$ maior que a normal, não tem nenhum fundamento seguro na ciência. Ao contrário, o sistema Terra já poderá estar fadado a uma mudança irreversível, mesmo que implementemos na totalidade a redução recomendada de $60 \%$ das emissões. 
Apenas as exalações da respiração e outras emissões gasosas de quase 7 bilhões de pessoas na Terra, seus animais de estimação e gado são responsáveis por $23 \%$ de todas as emissões de gases de efeito estufa. A isto devemos acrescentar o combustível fóssil queimado que totaliza cerca da metade de todas as emissões de dióxido de carbono. Neste sentido, somos parte do sistema Terra, inseparáveis dele, e nosso estilo de vida leva à conclusão de que há pouco tempo para agir sobre o clima em transformação. Não é a pegada de carbono isoladamente que prejudica a Terra, mas a pegada das pessoas.

A civilização industrial contemporânea não pode se ajustar para sobreviver em um planeta superpovoado e com poucos recursos, pensando que o progresso técnico poderá nos livrar dessa situação. Para o autor, todas as discussões sobre desenvolvimento sustentável perdem o sentido diante do ritmo crescente de derretimento do gelo polar, de elevação dos níveis do oceano e de migração das zonas climáticas. É possível, por meio da geoengenharia, atenuar algumas das consequências iniciais do aquecimento, mas é mais provável que em poucas décadas a Terra deixe de ser o habitat de quase 7 bilhões de seres humanos; ela se salvará quando liquidar todos exceto aqueles que partirem para regiões mais frias ainda férteis. Entretanto, para sustentar o clima e a composição da Terra, Gaia precisa dos ecossistemas, das florestas e outras vegetações do solo e das algas do oceano para sustentar a vida.

Muitos climatologistas não concordam com a visão do autor. Entretanto, para Lovelock, os modelos climáticos evoluíram há pouco tempo das necessidades de curto prazo da previsão do tempo e são ainda incapazes de prever o clima com confiança suficiente. Além disso, eles são limitados por uma teoria climática baseada quase integralmente na física atmosférica. Todos os modelos climáticos são bastante incompletos; as melhores medidas do calor absorvido pela Terra não é a temperatura média global, mas a elevação do nível do mar, originada do derretimento das geleiras no solo e a expansão do oceano à medida que ele se aquece. $\mathrm{O}$ autor nota que o nível do mar sobe progressivamente, mas a temperatura média global flutua ano a ano.

Por outro lado, em 1980 e antes disso a área do oceano Ártico coberta de gelo flutuante durante o verão era de aproximadamente 10 milhões de quilômetros quadrados de gelo e, em 2007 tinha caído a 4 milhões de quilômetros quadrados. Se o derretimento continuar nesse ritmo, o Ártico, no verão, estará quase sem gelo num prazo de quinze anos, ao contrário da previsão de climatologistas que situam essa data depois de 2050. A quantidade de calor que a Terra recebe do Sol, à medida que o gelo flutuante derrete, se aproxima de $70 \%$ do aquecimento causado por toda a poluição por dióxido de carbono atualmente. 
Outra evidência do aquecimento global é o declínio progressivo na população de algas oceânicas, aumentando em 15\% nos últimos nove anos a área estéril do aquecimento global. Isto porque as algas em declínio já não podem esfriar a Terra pela remoção de dióxido de carbono do ar.

As dissensões entre os partidários da teoria de Gaia e os climatologistas é que esta teoria é uma ciência interdisciplinar. Examinando as interações entre o mundo biológico, o físico e o químico, pode-se perceber como o ar foi mantido, antes que os homens começassem a modificá-lo, numa composição constante para sustentar um clima habitável. Como explica o nosso autor,

\begin{abstract}
A geofisiologia vê os organismos da Terra evoluindo por meio da seleção natural darwiniana num ambiente que é o produto de seus ancestrais, e não simplesmente uma consequência da história geológica da Terra. Logo, o oxigênio da atmosfera é quase integralmente o produto dos organismos fotossintéticos, e sem ele não haveria animais nem invertebrados nem queimaríamos combustíveis, lançando dióxido de carbono no ar. Acho surpreendente que os biólogos tenham levado tanto tempo, mesmo que de má vontade, para reconhecer que os organismos adaptaram-se não ao mundo estático, cômoda mas erroneamente descrito por seus colegas geólogos, mas a um mundo dinâmico construído pelos próprios organismos.
\end{abstract}

Nesse sentido, a Terra é um sistema interativo dinâmico, ou, de alguma forma, vivo. Deixar de considerar os organismos vivos como os seres humanos e as espécies dependentes de plantações e gado como parte integrante do sistema climático, invalida a maioria dos modelos climáticos. A pergunta crucial é: a que velocidade está se aquecendo? E a resposta é mais bem dada pela observação do nível do mar, como dito anteriormente. Nesse sentido, é possível que as previsões climáticas sejam profundamente conservadoras em relação ao que prevê a Teoria de Gaia.

Uma alternativa aventada ao aquecimento global é a geoengenharia, como por exemplo, um aerossol estratosférico para atenuá-lo. Entretanto isto não evitaria a acidificação dos oceanos, o que levaria a novos remédios em uma sequência indefinível. Para evitar que o planeta termine por sacrificar a humanidade da mesma forma como eliminamos outras espécies ao transformarmos o ambiente em outro, onde sua sobrevivência é difícil, nas palavras do autor "a alternativa é a aceitação do sacrifício natural maciço da humanidade e a volta a uma Terra que se regula livremente". Para que isto não se transforme em um derrotismo amargo é necessária a adaptação à mudança climática fazendo uso das futuras 
ilhas de refúgio no mundo que escaparão do calor e da seca, buscando fontes alternativas de alimentos e energia.

Esta é uma situação parecida com o aquecimento global do início do período Eoceno, quando não houve uma grande extinção das espécies. Isto porque a vida teve tempo para mudar para as regiões mais frias do Ártico e da Antártida e permanecer lá até que o planeta voltasse a esfriar o suficiente. Entretanto isto envolve a assunção de uma grande responsabilidade e deveres humanos, antes que os seus direitos de utilizar Gaia como se não fôssemos parte dela.

Um problema que tem sido colocado é o uso de fontes alternativas de energia que minimizem o aquecimento global. Lovelock investiga essas alternativas em seus livros, embora reconheça que a substituição levaria tempo e que as linhas de transmissão de alta potência e longa distância demandam tempo para cruzar as regiões da Terra onde seriam necessárias. O sucesso da energia solar depende muito da rapidez com que pode ser implementada, e não podemos esperar muito tempo. Em curto prazo, a combustão fóssil e a energia da fissão nuclear deverão ser as alternativas viáveis. O autor faz uma análise paciente aí da viabilidade e segurança da energia nuclear tal como é utilizada em larga escala na Fança.

Em relação à energia renovável, ou energia gerada de recursos naturais como o vento, luz solar, água corrente, marés, calor geotérmico, biombustíveis e biomassa, sua análise envolve aspectos técnicos e econômicos complexos, e nem sempre consiste na melhor solução. A energia eólica, por exemplo, demanda grande extensão de terra para instalação de turbinas, ventos soprando na altura certa a maior parte do tempo e o apoio de uma central de combustível fóssil quando o vento soprasse acima ou abaixo da velocidade média. Também a biomassa e os biocombustíveis enfrentam o problema de alterar substancialmente regiões em que a natureza deve ser deixada à disposição das necessidades inerentes a Gaia. Ademais, elas competem com a produção de alimentos e em muitas regiões do mundo a produção de energia verde tem levado à alta do preço dos alimentos, como na Índia e na África.

Além disso, a necessidade de comida não pode depender de modernas fazendas de agronegócios, por ameaçarem ou extinguirem zonas que deveriam ser preservadas. Se a Amazônia, por exemplo, continuar em seu ritmo de transformação de florestas em fazendas de gado e outras explorações, provavelmente o Brasil sofrerá uma crise aguda de água. É possível e necessário pensar em comida sintetizada a partir de dióxido de carbono, nitrogênio, água e alguns minerais, deixando em segundo plano a forma ineficiente de produzir comida criando bois e carneiros, ou favorecendo a criação de animais menores como aves e suínos. 
A maior parte das pessoas vive agora, no mundo, em cidades muito dependentes de eletricidade, de seu fornecimento constante e invariável. Quase todas as atividades humanas diárias dependem de eletricidade. Isso coloca na pauta a alternativa da energia nuclear. Para o autor, a Terra provavelmente mudará para um estado 4\% mais quente, e com isso apenas uma parte limitada de terras estará disponível para ser dividida com ecossistemas naturais. Para ele, seria imprudente utilizar mais de 30\% dessa área, já que o restante deve ser preservado como ecossistemas necessários à autorregulação do planeta, especialmente diante da desertificação dos oceanos. Isso leva a políticas como a controle de natalidade, por exemplo, que envolve uma redefinição do papel e do poder das mulheres no mundo.

Essa visão de mundo de Lovelock vai acompanhada de uma crítica ao movimento verde, na medida em que este ignora com frequência que somos inseparáveis de Gaia. O mundo da natureza parece ser percebido à parte, perdendo-se o conceito de Gaia ou do mundo da natureza exceto para fins de diversão. Não sentimos nos mecanismos de produção e de mercado nossa dependência da natureza. A região rural é vista apenas como um serviço da cidade, para ser usada como seu suporte de vida, um lugar para fazendas de agronegócios, para as centrais de tratamento de esgotos, os reservatórios e um território cheio de energia alternativa para manter a cidade funcionando. Há além disso, os parques temáticos no campo com acesso fácil à auto-estrada. $\mathrm{O}$ movimento verde perdeu a aura da natureza como algo romântico, como era aos primeiros ecologistas e verdes, para se transformar em uma forma de indústria e subsídios verdes sem focar os verdadeiros problemas da sustentabilidade da Terra e da vida.

Como assinala Crispin Tickell, prefaciador de A Vingança de Gaia (2006), o essencial é perceber que

O calor do Sol sobre a Terra vem gradualmente aumentando, e a autorregulação da qual depende toda a vida está correndo perigo. Olhando o ecossistema global como um todo, vemos que o aumento da população humana, a degradação das terras, o esgotamento dos recursos, o acúmulo de resíduos, todo tipo de poluição, a mudança climática, os abusos da tecnologia e a destruição da biodiversidade em todas as suas formas constituem juntos uma inédita ameaça ao bem-estar humano, desconhecida pelas gerações anteriores.

Como assinala Lovelock, quando ouvimos notícias sobre a catástrofe de Nova Orleans, terremotos e tsunamis, percebemos que a terra tem um poder de matar, e que estes eventos são muito menores do que o que ocorrerá se a Terras recuar ao estado quente de 55 milhões de anos atrás, já que nossas vidas dependem de uma Terra sadia. Mais importante mesmo que salvar a humanidade é salvar Gaia. Isto tem relação imediata com a forma como 
concebemos o desenvolvimento econômico e social, e como uma ação transformadora pode atingir os interesses das grandes companhias que envenenam o campo ou poluem nossa vida em diversos sentidos acima explorados. Tem relação também com a assimetria de poder que os humanos ostentam, entre regiões e camadas sociais, exigindo uma geopolítica holística baseada em valores que temos de criar e estabilizar na vida de cada habitante da Terra. Portanto, há desafios para enfrentar hoje que envolvem também os fundamentos éticos do conhecimento desenvolvido pela ciência.

\section{REFERÊNCIAS}

LOVELOCK, James. Gaia: Alerta Final, Rio de Janeiro: Intrínseca, 2010.

LOVELOCK, James. A Vingança de Gaia, Rio de Janeiro: Intrínseca, 2006. 